\section{Schlafbezogene Halluzinationen}

Helga Peter

Marburg, Deutschland

\section{Englischer Begriff}

sleep related hallucinations

\section{Definition}

Sie werden zu den $\triangleright$,Parasomnien“" gezählt und treten ausschließlich in Verbindung mit dem Schlaf auf, entweder beim Einschlafen (hypnagog) oder beim Aufwachen (hypnopomp), sowohl nachts als auch beim Tagschlaf. Die Halluzinationen können alle Sinnesmodalitäten betreffen und sowohl angenehme wie auch furchterregende Inhalte haben. Typischerweise werden die Eindrücke als sehr realistisch erlebt und sind für die Betroffenen beängstigend und verunsichernd. Differentialdiagnostisch kann der Ausschluss einer $>$ „Psychose" erforderlich sein. Schlafbezogene Halluzinationen gehören auch zu den fakultativen Symptomen bei > ,Narkolep$\mathrm{sie}^{\prime \prime}$. 